\title{
Multimorbidity and cardiovascular disease: a perspective on low- and middle-income countries
}

\author{
Friedrich Thienemann ${ }^{1,2,3}$, Ntobeko A. B. Ntusi ${ }^{2}$, Edouard Battegay ${ }^{1,4}$, Beatrice U. Mueller ${ }^{1}$, \\ Marcus Cheetham ${ }^{1,4}$
}

${ }^{1}$ Department of Internal Medicine, University Hospital Zurich, University of Zurich, Zurich, Switzerland; ${ }^{2}$ Department of Medicine, Faculty of Health Science, University of Cape Town, Cape Town, South Africa; ${ }^{3}$ Wellcome Centre for Infectious Diseases Research in Africa, Institute of Infectious Diseases and Molecular Medicine, Faculty of Health Science, University of Cape Town, Cape Town, South Africa; ${ }^{4}$ University Research Priority Program "Dynamics of Healthy Aging”, University of Zurich, Zurich, Switzerland

Contributions: (I) Conception and design: F Thienemann, M Cheetham; (II) Administrative support: None; (III) Provision of study material or patients: None; (IV) Collection and assembly of data: None; (V) Data analysis and interpretation: None; (VI) Manuscript writing: All authors; (VII) Final approval of manuscript: All authors.

Correspondence to: Edouard Battegay, MD, FACP. Professor of Internal Medicine, Director, Department of Internal Medicine, University Hospital Zurich, Rämistrasse 100, 8091 Zurich, Switzerland. Email: edouard.battegay@usz.ch.

\begin{abstract}
New and changing patterns of multimorbidity (MM), i.e., multiple concurrent acute or chronic diseases in a person, are emerging in low- and middle-income countries (LMICs). The interplay of underlying population-specific factors and lifestyle habits combined with the colliding epidemics of communicable and non-communicable diseases presents new disease combinations, complexities and risks that are not common in high-income countries (HICs). The complexities and risks include those arising from potentially harmful drug-drug and drug-disease interactions (DDIs), the management of which may be considered as MM in the true sense. A major concern in LMICs is the increasing burden of leading cardiovascular diseases, prevalence of associated risk factors and co-occurrence with other morbidities. New models of MM management and integrated care can respond to the needs of specific multimorbid populations, with some LMICs making substantial progress (e.g., integration of tuberculosis and HIV services in South Africa). But there is a dearth of relevant data on the changing patterns and underlying factors and determinants of MM, the associated complexities and risks of DDIs in MM management, and the barriers to integrated care in LMICs. This requires careful attention.
\end{abstract}

Keywords: Multimorbidity (MM); cardiovascular disease (CVD); poverty; low income countries; middle income countries; Africa

Submitted May 31, 2019. Accepted for publication Sep 06, 2019.

doi: $10.21037 / \mathrm{cdt} .2019 .09 .09$

View this article at: http://dx.doi.org/10.21037/cdt.2019.09.09

\section{Introduction}

Multimorbidity (MM) refers to the presence of multiple concurrent acute or chronic diseases within a person (Box 1) $(1,4)$. This simple disease count-based definition of MM dominates epidemiologic research, especially in highincome countries (HICs). Comparatively little is known about the burden of MM in low- and middle-income countries (LMICs) (5-7). This is in part because studies have largely focused on single diseases (8). The variation across studies in the choice of study design, methods, and measures limits comparability of findings on the distribution and determinants of MM disease burden. Nevertheless, there is mounting recognition that there are different and changing demographic and epidemiological patterns of MM within and across different HICs and LMICs populations, that a complex interplay of population-specific demographic, economic, social, cultural and psychological 
Box 1 Definitions of multimorbidity

"Multimorbidity is the co-occurrence of multiple chronic or acute diseases and medical conditions within one person" (1)

In contrast to an index disease taking central place in the disease combination, multimorbidity is the "co-existence of two or more chronic conditions, where one is not necessarily more central than the others" (2)

"Multimorbidity is defined as any combination of chronic disease with at least one other disease (acute or chronic) or bio-psychosocial factor (associated or not) or somatic risk factor" (3)

factors, and lifestyle habits (e.g., lack of exercise, unhealthy diets, smoking or alcohol consumption) contribute to these differences, and that these patterns and contributory factors require careful attention if healthcare delivery is to respond adequately to the needs of specific multimorbid populations $(9,10)$.

Multimorbid patients with cardiovascular disease (CVD), chronic kidney and lung disease, and concurrent other noncommunicable diseases (NCDs) and infectious diseases (and their care providers) face major challenges. These challenges require careful attention, particularly in LMICs. The urban community in LMICs, especially in sub-Saharan Africa (SSA), has undergone an immense epidemiological transition towards cardiac risk factors. Besides the shift in the global burden of hypertension from HICs to LMICs over the past decades, the number of adults living with diabetes has increased from 108 million in 1980 to 422 million in 2014 $(11,12)$. This has led to a dramatic increase in ischaemic heart disease, stroke, hypertensive heart failure, and atrial fibrillation. In addition, traditional CVDs are still prevalent in LMICs, such as rheumatic heart diseases, cardiomyopathy, undiagnosed hypertension, untreated congenital heart disease, and endomyocardial fibrosis. Chronic kidney disease does have numerous causes, but diabetes and hypertension are the two main risk factors. In the Global Burden of Disease Study 2017, chronic obstructive pulmonary disease (COPD) ranked as the seventh leading cause of early death (13). NCDs interact in a complex fashion with the top three global infectious diseases epidemics: humanimmunodeficiency virus/acquired immune deficiency syndrome (HIV/AIDS), tuberculosis, and malaria. In 2017, 36.9 million people were living with HIV, with $95 \%$ of new HIV infections occurring in Eastern Europe, central Asia, the Middle East, and North Africa (14). Tuberculosis remains one of the top 10 causes of death globally. About 10 million new infections occurred in 2017, 9\% of which were people living with HIV (72\% of them in Africa) (15). In the same year, the World Health Organization (WHO) reported 219 million cases of malaria worldwide (16). In addition, chronic parasitic infections such as schistosomiasis and filariasis may interact with NCDs and lead to substantial chronic disease morbidity, e.g., schistosomiasis-associated pulmonary arterial hypertension (17).

\section{Demographic transition and MM}

The demographic transition to older populations is a driver of MM prevalence (18). Globally, fertility and mortality rates have dropped substantially, except in SSA where in many regions the onset and pace of change are substantially delayed (19). Life expectancy rates in HICs show some stagnation and even decline, while the increasing rate of population aging in LMICs is strong and expected to continue for years to come $(20,21)$. Differences in pace may be set in the context of other differences between HICs and LMICs. For instance, average life expectancy at birth (in 2016) reached 83.3 years in Switzerland and 78.6 years in the United States, but only 63.6 years in South Africa, 52.9 years in Lesotho, and 53.1 years in Sierra Leone (Figure 1) $(22,23)$. Importantly, recent data indicates that the severity of MM (based on disease count) increases with age in both HICs and LMICs $(10,24)$, but the rates of prevalence in older populations are fundamentally different. MM affects $66.1 \%$ of those aged 65 and over in HICs and $7.8 \%$ of those aged 60 and over in LMICs $(10,25,26)$.

Population aging is also a major driver of the global increase in CVD morbidity and mortality, with over 18 million CVD-related deaths globally in 2017 (27). In some countries in SSA, increasing life expectancy and the ageing population are linked to improvements in access and delivery of healthcare and control of infectious diseases, especially HIV/AIDS (28). As older populations are more vulnerable, the burden of leading CVDs, the prevalence of their risk factors, and their co-occurrence with other morbidities is likely to increase in LMICs $(8,29)$. Risk factors include increasing body mass index (particularly affecting women in South Africa), systolic blood pressure (in East Africa), alcohol (particularly in southern regions of 
Life expectancy, 2017*

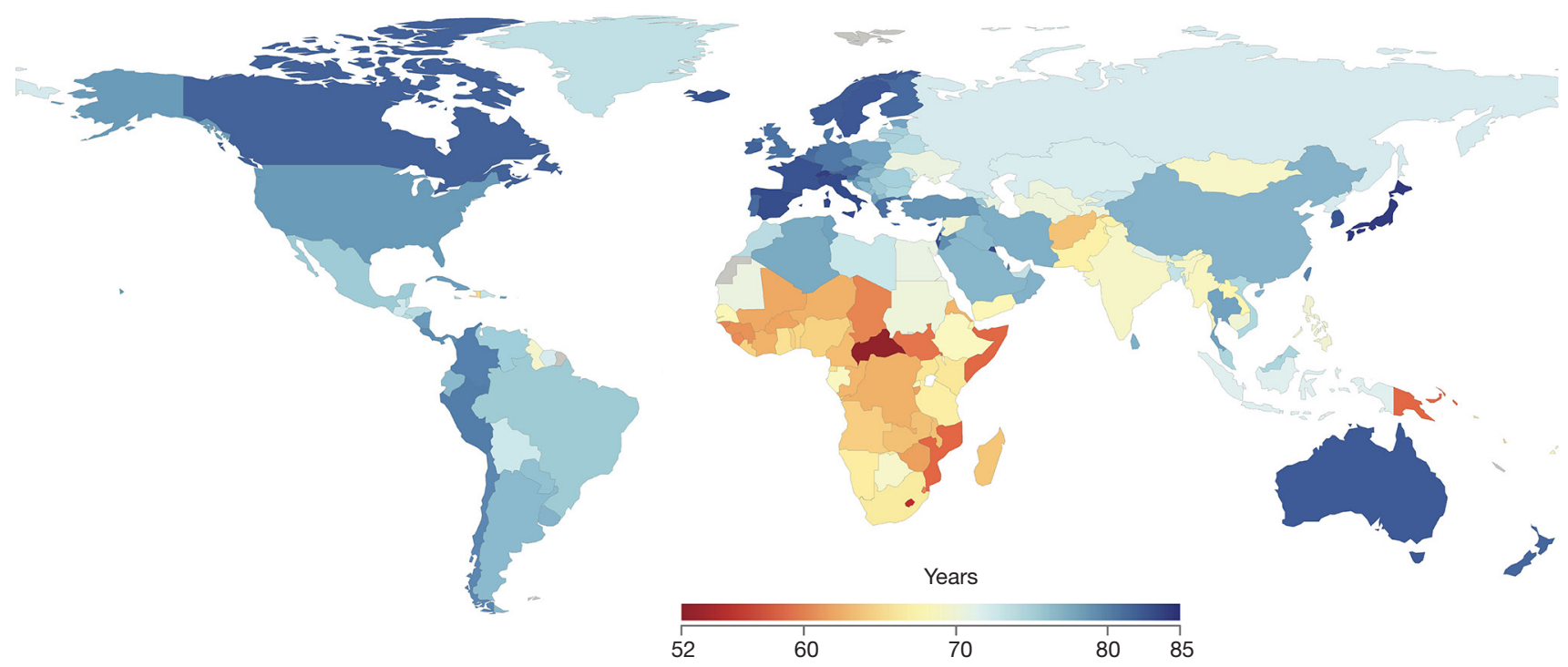

*Data shown in the figure represent

life expectancy at birth for both sexes.

Figure 1 Life expectancy at birth for both sexes. Findings from the Global Burden of Disease Study 2017 (13).

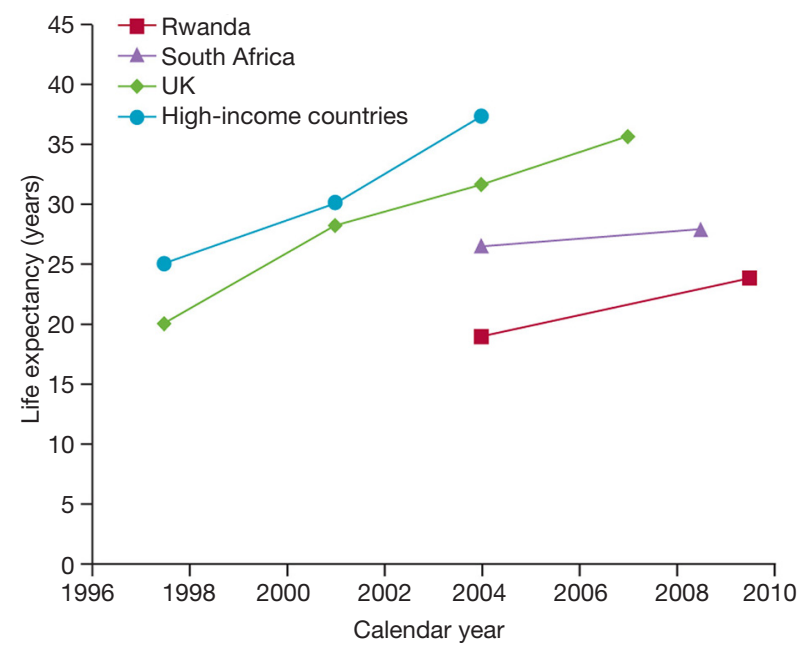

Figure 2 Trends in life expectancy for individuals initiating antiretroviral therapy at age 35 years from Rwanda, South Africa, United Kingdom (UK), and high-income countries in North America and Europe. Published by Egger \& Johnson in The Lancet Global Health in 2015 (38).

SSA), tobacco use, and physical inactivity (30).

However, a focus on aging can divert attention away from MM burden in younger age groups (31). MM affects all age groups in HICs (32), as shown in Australia where 2.1\% of multimorbid persons are less than 60 years of age (33). But data are limited in LMICs. For example, in SSA younger adults are increasingly predisposed to NCDs, especially CVDs, this risk being linked to urbanization and lifestyle changes (34-36). In South Africa, 20\% of women aged 15 years or older are severely obese (body mass index $\geq 35$ ). Most of these are among coloured and black African populations (26\% and $20 \%$, respectively), affecting $17 \%$ of women of 25-34 years. Tobacco is consumed daily by as much as $6 \%$ of women and $30 \%$ of men, and alcohol abuse affects $5 \%$ of women and $28 \%$ of men (37).

South Africa has the biggest HIV epidemic in the world, with 7.2 million people living with HIV in 2017 (14). South Africa has introduced extensive measures to tackle this epidemic by rolling out the largest antiretroviral therapy (ART) program globally. In 2017, 86\% of people living with HIV were aware of their status and $61 \%$ were receiving ART. Globally, this is the most successful campaign in tackling the HIV epidemic, starkly improving life expectancy rates in South Africa. Outside of South Africa, life expectancy rates have improved dramatically for those starting ART (Figure 2).

The aging HIV patient has an increased risk of chronic diseases compared with non-infected adults. More prevalent co-morbidities in people living with HIV include 
Box 2 Typical multimorbidity combinations, or clusters, in high-income countries

Cardiovascular: coronary heart disease, cardiac insufficiency, stroke, hypertension, diabetes, dyslipidaemia, kidney problems

Psychiatric multimorbidity with alcohol and substances abuse, depression, personality disorder: alcohol-induced liver disease or hepatitis C, often in combination

Falls, frailty, Parkinson's disease, depression, cognitive deficits, social isolation

Chronic obstructive pulmonary disease, depression

Pain, depression, anxiety

Frailty, dementia, depression

The severity of the individual diseases can differ greatly between individuals. This may relate to social factors (e.g., social support and caregiver involvement in health management) that influence disease development

CVDs, kidney and liver diseases, cancer, and cognitive impairment (39). In addition, HIV-associated tuberculosis poses an additional risk for people living with HIV to develop post-tuberculosis chronic lung disease, such as fibro-cavitation and bronchiectasis, leading to a COPDtype disease often referred to as tuberculosis obstructive pulmonary disease (TOPD), and, if hypoxia is present, pulmonary hypertension, cor pulmonale, and right heart failure (17).

\section{GDP per capita and MM}

MM prevalence shows a positive relationship with gross domestic product (GDP) per capita (10). For example, Switzerland has a GDP per capita of 80,189 USD in 2017 and belongs to the $30 \mathrm{HICs}$ with a mean $66.1 \% \mathrm{MM}$ prevalence in the elderly population (over 65 years) (26). South Africa, a middle-income country, has a GPD per capita of 3,589 USD and a MM prevalence of $30.1 \%$ in the elderly population (in 2013) (10). In South Africa, the risk of chronic disease and $M M$ increases with increasing income (40). The relationship between MM and GDP is, however, subject to large population-specific differences in socio-economic status within countries (41). The risk of $M M$ is higher in the highest income subpopulation of the low-income country Bangladesh (6), whereas lower income associates with higher MM rates in Scotland (41). All available studies show higher MM risk in subpopulations with higher deprivation levels (40).

NCDs are increasing in LMIC subpopulations with increasing socio-economic status (42). In SSA, improving socio-economic status enhances the risk of CVD as risk factors become more prevalent. Epidemiological transitions and changes in diets and unhealthy processed foods are affecting rural and poor urban communities in SSA (43-45). These dietary changes are income-related and associated with main CVD risks, diabetes, obesity, and hypertension. The impact of change in income is not just affecting adults. Higher-income communities in Africa reveal enhanced obesity and other CVD risk factors, even in school children (46-48).

\section{Health transition and MM}

LMICs are subject to a rapid emergence of new patterns and trends in $M M$ disease in the form of a health transition to NCDs (49). Combined with the high rates of HIV, tuberculosis and malaria (the top three infectious chronic diseases), this transition has led to the so-called colliding epidemics of communicable and NCDs in LMICs (also referred to as the double burden of disease), especially in SSA (50). Within SSA there are regional differences in the pace of the health transition and the underlying distributions of age, sex and socioeconomic factors (51). However, the double burden of communicable and NCDs has led to new multimorbid disease constellations of cooccurring communicable and NCDs that are not prevalent in HICs (Box 2).

At the beginning of this decade, multiple reports from Africa described the colliding epidemics. In response to this, the WHO developed a practical policy proposal for primary health care. The aim of this policy was to harness the potential for primary care clinics in SSA to prevent and treat NCDs within the primary care tuberculosis/ HIV programs (52). Reports from India have highlighted an additional burden - the triple burden of diseaseaffecting the population and general health care system: Reproductive health-related diseases such as haemorrhage, sepsis abortion complications, and pre-eclampsia/eclampsia were leading to increased maternal mortality (53). In addition, late maternal deaths due to CVDs have been 
Box 3 Drug-drug and drug-disease interactions

Interactions within a patient have three basic elements (60):

Drug-drug interactions (pharmacokinetic interactions): interactions between drugs are broadly covered scientifically, with extensive databases

Drug-disease interactions (pharmacodynamic interactions): the medication for one disease is harmful for another disease of the patient (e.g., anticoagulation and bleeding)

Disease-disease interactions: the patient's diagnostic and treatment process changes due to the simultaneous presence of two or more diseases

declared as a neglected responsibility and are due to cardiac diseases in maternity such as peripartum cardiomyopathy (54,55). The Department of Health in South Africa has also referred to a quadruple burden of disease, defining four colliding epidemics. This four-way collision comprises, firstly, communicable diseases (HIV and tuberculosis), second, NCDs, third, maternal, new-born and child healthrelated morbidity and mortality, and, finally, interpersonal violence and injuries (56).

Rapid urbanization and climate change add another level of complexity to global health. More than half of the world's population live in urban areas of cities and 21 of the 30 fastest-growing cities are on the African continent (57). As mentioned above, urbanisation may lead to changes in diet and exercise, but also increases the risk of infectious diseases such as HIV, tuberculosis, Dengue, Zika, and many others. Causes are multifactorial from overcrowding and poor living conditions, violence and abusive behaviours, to health risks due to climate change that affects quantity and quality of food and water, increased air pollution, and alteration of pathogens and vector-borne diseases (58).

\section{MM and interactions between diseases and drugs}

The emergence of new combinations of co-occurring health issues arising from the double-to-quadruple burdens of disease also leads to increasing complexity and risk in $M M$ management and healthcare $(50,59)$. This relates to the potentially harmful effects of drug-drug and drug-disease interactions (DDIs, Box 3) (61). Limited evidence-based guidelines for $M M$ (62), even for more prevalent forms of MM (60), enhances the reliance upon clinical guidelines that are intended for the treatment of single diseases (63). These guidelines do not adequately address the combined and cumulative risk of DDIs or adequately guide the clinician through the decision-making uncertainties and conflicts when trying to reconcile potentially harmful DDIs with a suitable therapeutic strategy personalized to the patient's specific disease combination (64). Typical conflicts include concurrent bleeding (e.g., gastrointestinal, head injury) and anticoagulation (e.g., arterial fibrillation, pulmonary embolism), chronic kidney disease and metformin therapy for diabetes, steroid therapy (e.g., prednisone) and hypertension or diabetes.

Physicians and nurses often consider the challenges presented by DDIs as MM in the true sense (65). For example, in South Africa, DDIs may include HIV-infection with increased risk of CVD (66). The incidence of HIVassociated dilated cardiomyopathy prior to initiating ART was 15.9/1,000 per annum and the prevalence of HIVassociated pulmonary hypertension $1.6 \%$ to $5.0 \%$ (67). $\mathrm{HIV}$-infection also amplifies the risk for ischaemic heart disease. HIV-associated dilated cardiomyopathy is even considered a criterion for WHO stage IV disease (also referred to as "AIDS") (68). Besides increased cardiovascular risk in HIV-infected individuals compared with the general population in HICs and LMICs, ART may further aggravate the risk of CVD $(67,69,70)$. This may be due to direct adverse drug reactions or via associated dyslipidaemia and insulin resistance. Table 1 summarizes the main classes of antiretroviral drugs, their effects on lipid and glucose metabolism, and the potential for contributing to the risk of CVD $(67,71)$. In daily clinical routine, these complexities may diminish because the diseases aggregate in typical MM clusters (Box 2) (72,73). It should be noted that some DDIs effects may be protective, for example, sickle cell anaemia may provide protection against severe malaria $(74,75)$. The most comprehensive guidelines to manage the complexity of MM in HIV-infection are the European AIDS Clinical Society Guidelines for treatment of HIV-infected adults (76).

\section{Integrated care for MM in LMICs}

In countries like South Africa, demographic change is interacting with transitional change. The shift towards 
Table 1 Main classes of antiretroviral drugs and their impact on lipid and glucose metabolism and coronary artery disease

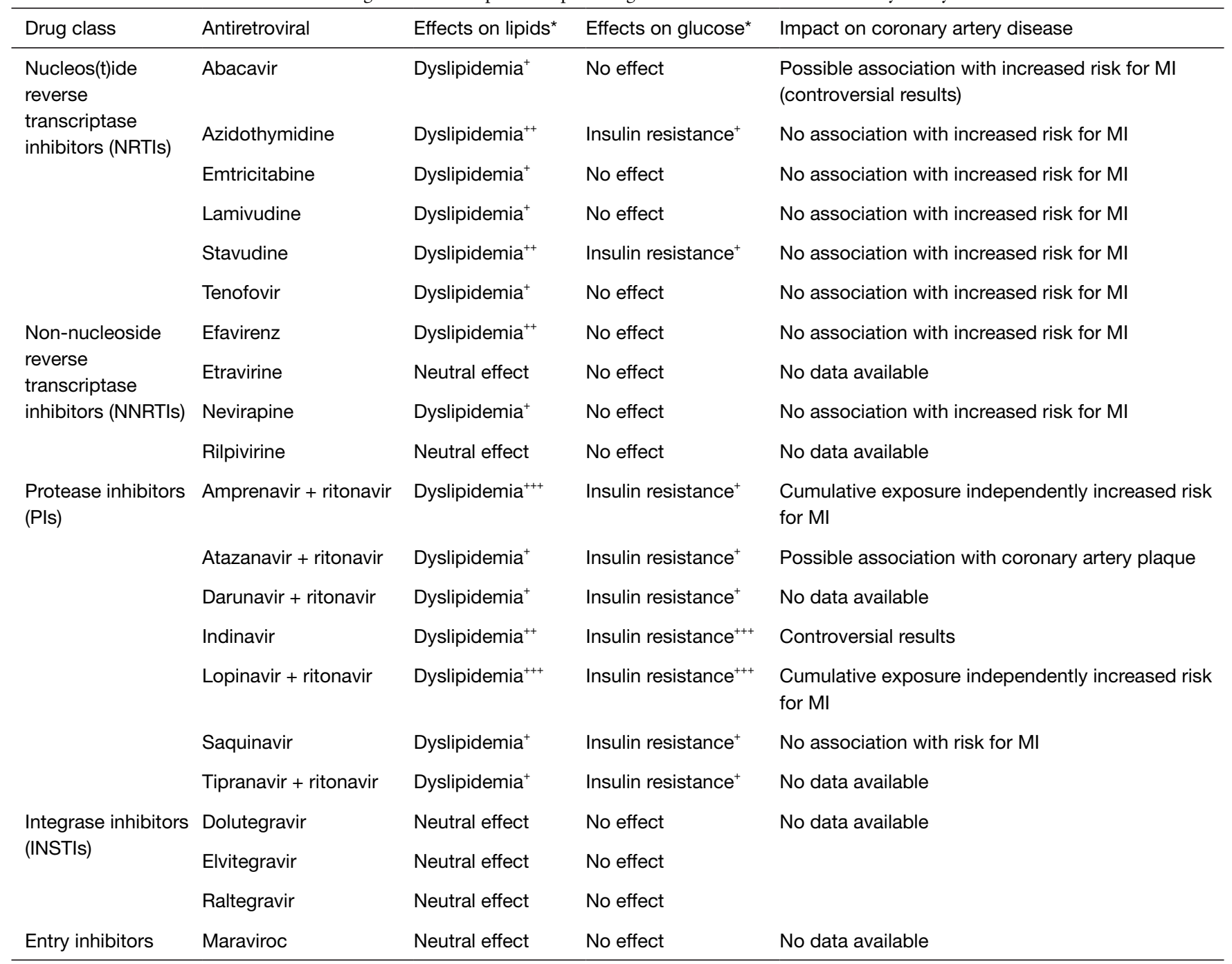

Adapted from Thienemann et al. 2013 (67). *, Dyslipidemia defined as increased total cholesterol (TC), low-density lipoprotein cholesterol (LDL), triglycerides and decreased high-density lipoprotein cholesterol (HDL); ${ }^{+}$, weak effect; ${ }^{++}$, moderate effect; ${ }^{++}$, important effect. MI, myocardial infarction.

an increasing elderly population may add to the double burden of disease of communicable and NCDs $(77,78)$. These changes require an adequate response for specific multimorbid populations. In 1978, the Declaration of Alma-Ata was the first international attempt by the WHO to adopt the primary health care model to promote health for all (79). However, many LMICs were unable to provide universal access to health care. By the end of the last century the advent of the three largest infectious epidemics $\mathrm{HIV}$, tuberculosis and malaria were cause and consequence of this failure (80). The tremendous global response to the HIV epidemic ensured that programmatic HIV and tuberculosis clinics were established to fight the epidemics. In the United Nations General Assembly 2016, the international community adopted a declaration to end the HIV epidemic by 2030 and to "take HIV out of isolation" making the Declaration of Alma-Ata more important than ever with the re-integration of HIV and tuberculosis into the primary health care model (81). According to the United Nations, integrated primary health care services shall include "HIV, tuberculosis, viral hepatitis, sexually transmitted infections, NCDs, including cervical cancer, drug dependence, food and nutrition support, maternal, child and adolescent health, men's health, mental health and 
sexual and reproductive health, and to address gender-based and sexual violence" (81).

In recent years, the integration of tuberculosis and HIV services has been a major focus of research globally. Tuberculosis-HIV service integration can occur along a continuum, from encouraging referral between services to intensified screening for co-infection and full-service integration in one location provided by a single team. South Africa has made substantial progress in the integration of tuberculosis and HIV services. Many clinics in the country now offer a further level of integration that includes screening and management of sexually transmitted infections and NCDs (COPD, CVD, diabetes and cancer). Indeed, recent reports confirm data from tuberculosis and HIV services in South Africa, showing that patients who received dual tuberculosis and HIV treatment were significantly less likely to die or drop out when receiving care from one clinical team compared with non-integrated services (82). Despite this compelling evidence, barriers to integration remain: one of these is the fear that when vertical services are integrated with others or into the mainstream of health services, quality is compromised as services confront overall systems weaknesses (83). There is a strong need for integration efforts to focus on systems level strengthening for better outcomes in MM, especially with regards to supervision and support systems for primary health care (84). The concept of integration goes beyond the idea of bringing together two or more pre-existing vertical services to considerations of how to expand health service entitlements by introducing new services into the mainstream of healthcare. Integration of services does not necessarily have to occur through the channel of the primary health care system but may occur at every level of care or outside clinical centres.

\section{Summary and conclusions}

The confluence of demographic and health transitions and the emergence of new combinations of co-occurring diseases (in particular the double to quadruple burden of disease) in LMIC populations has altered the picture of complexity and risk that is commonly associated with MM management in HICs. This picture is better documented in HICs, providing therefore a vantage point from which to view the rapid emergence of different patterns and trends in MM disease in LMICs. The lack of scientific evidence and operationally applicable guidelines for managing DDIs in HICs serves to highlight the challenges facing MM management LMICs.

\section{Acknowledgments}

Funding: None.

\section{Footnote}

Provenance and Peer Review: This article was commissioned by the Guest Editor (Ntobeko A. B. Ntusi) for the series "Cardiovascular Diseases in Low- and Middle-Income Countries" published in Cardiovascular Diagnosis and Therapy. The article was sent for external peer review organized by the Guest Editor and the editorial office.

Conflicts of Interest: All authors have completed the ICMJE uniform disclosure form (available at http://dx.doi. org/10.21037/cdt.2019.09.09). The series "Cardiovascular Diseases in Low-and Middle-Income Countries" was commissioned by the editorial office without any funding or sponsorship. NABN served as the unpaid Guest Editor of the series. The other authors have no other conflicts of interest to declare.

Ethical Statement: The authors are accountable for all aspects of the work in ensuring that questions related to the accuracy or integrity of any part of the work are appropriately investigated and resolved.

Open Access Statement: This is an Open Access article distributed in accordance with the Creative Commons Attribution-NonCommercial-NoDerivs 4.0 International License (CC BY-NC-ND 4.0), which permits the noncommercial replication and distribution of the article with the strict proviso that no changes or edits are made and the original work is properly cited (including links to both the formal publication through the relevant DOI and the license). See: https://creativecommons.org/licenses/by-nc-nd/4.0/.

\section{References}

1. van der Akker M. Comorbidity or multimorbidity. Eur J Gen Pract 1996;2:65-70.

2. Boyd CM, Fortin M. Future of Multimorbidity Research: How Should Understanding of Multimorbidity Inform Health System Design? Public Health Rev 2010;32:451-74.

3. Le Reste JY, Nabbe P, Manceau B, et al. The European General Practice Research Network presents a comprehensive definition of multimorbidity in family medicine and long term care, following a systematic review of relevant literature. J Am Med Dir Assoc 2013;14:319-25. 
4. Bayliss EA, Edwards AE, Steiner JF, et al. Processes of care desired by elderly patients with multimorbidities. Fam Pract 2008;25:287-93.

5. Zeba AN, Delisle HF, Renier G, et al. The double burden of malnutrition and cardiometabolic risk widens the gender and socio-economic health gap: a study among adults in Burkina Faso (West Africa). Public Health Nutr 2012;15:2210-9.

6. Khanam MA, Streatfield PK, Kabir ZN, et al. Prevalence and patterns of multimorbidity among elderly people in rural Bangladesh: a cross-sectional study. J Health Popul Nutr 2011;29:406-14.

7. Househam KC. Africa's burden of disease: the University of Cape Town Sub-Saharan Africa Centre for Chronic Disease. S Afr Med J 2010;100:94-5.

8. Lim SS, Vos T, Flaxman AD, et al. A comparative risk assessment of burden of disease and injury attributable to 67 risk factors and risk factor clusters in 21 regions, 1990-2010: a systematic analysis for the Global Burden of Disease Study 2010. Lancet 2012;380:2224-60.

9. Chung RY, Mercer S, Lai FT, et al. Socioeconomic Determinants of Multimorbidity: A Population-Based Household Survey of Hong Kong Chinese. PLoS One 2015;10:e0140040.

10. Afshar S, Roderick PJ, Kowal P, et al. Multimorbidity and the inequalities of global ageing: a cross-sectional study of 28 countries using the World Health Surveys. BMC Public Health 2015;15:776.

11. Collaboration NCDRF. Worldwide trends in blood pressure from 1975 to 2015: a pooled analysis of 1479 population-based measurement studies with 19.1 million participants. Lancet 2017;389:37-55.

12. WHO. Global report on diabetes. Geneva, Switzerland: World Health Organization, 2016.

13. (IHME) IfHMaE. Findings from the Global Burden of Disease Study 2017. In: Seattle, WA: IHME, 2018. 2018. Available online: http://www.healthdata.org/sites/default/ files/files/policy_report/2019/GBD_2017_Booklet.pdf. Accessed 28 May 20192019.

14. UNAIDS Data 2017. Geneva: UNAIDS; 2017. [cited May 2019]. Available online: https://www.unaids.org/sites/default/ files/media_asset/20170720_Data_book_2017_en.pdf

15. WHO. Global Tuberculosis Report 2018. Geneva, Switzerland: World Health Organization, 2018.

16. WHO. World malaria report 2018. Geneva, Switzerland: World Health Organization, 2018.

17. Thienemann F, Dzudie A, Mocumbi AO, et al. The causes, treatment, and outcome of pulmonary hypertension in Africa: Insights from the Pan African Pulmonary Hypertension Cohort (PAPUCO) Registry. Int J Cardiol 2016;221:205-11.
18. Vincent GK, Velkoff VA. The next four decades: The older population in the United States: 2010 to 2050. US Department of Commerce, Economics and Statistics Administration, US Census Bureau, 2010.

19. Bongaarts J, Casterline J. Fertility Transition: Is subSaharan Africa Different? Popul Dev Rev 2013;38:153-68.

20. Ho JY, Hendi AS. Recent trends in life expectancy across high income countries: retrospective observational study. BMJ 2018;362:k2562.

21. National Research Council (US) Panel on a Research Agenda and New Data for an Aging World. Preparing for an Aging World: The Case for Cross-National Research. The National Academies Collection: Reports funded by National Institutes of Health. Washington (DC): National Academies Press (US); 2001.

22. WHO. World health statistics 2019: monitoring health for the SDGs, sustainable development goals. Geneva, Switzerland: World Health Organization, 2019.

23. OECD. Organisation for Economic Co-operation and Development OECD Statistics. 2019. Available online: https://stats.oecd.org. Accessed 28 May 2019.

24. Salisbury C, Johnson L, Purdy S, et al. Epidemiology and impact of multimorbidity in primary care: a retrospective cohort study. Br J Gen Pract 2011;61:e12-21.

25. Islas-Granillo H, Medina-Solis CE, de Lourdes MarquezCorona M, et al. Prevalence of multimorbidity in subjects aged $\geq 60$ years in a developing country. Clin Interv Aging 2018;13:1129-33.

26. Ofori-Asenso R, Chin KL, Curtis AJ, et al. Recent Patterns of Multimorbidity Among Older Adults in HighIncome Countries. Popul Health Manag 2019;22:127-37.

27. World Health Statistics 2017: Monitoring health for the SDGs, Sustainable Development Goals. Geneva: World Health Organization; 2017. Licence: CC BY-NC-SA 3.0 IGO. [cited May 2019]. Available online: https://www.who. int/gho/publications/world_health_statistics/2017/en/

28. Bor J, Herbst AJ, Newell ML, et al. Increases in adult life expectancy in rural South Africa: valuing the scale-up of HIV treatment. Science 2013;339:961-5.

29. Kadiri S, Salako BL. Cardiovascular risk factors in middle aged Nigerians. East Afr Med J 1997;74:303-6.

30. Mensah GA. Descriptive epidemiology of cardiovascular risk factors and diabetes in sub-Saharan Africa. Prog Cardiovasc Dis 2013;56:240-50.

31. Britt HC, Harrison CM, Miller GC, et al. Prevalence and patterns of multimorbidity in Australia. Med J Aust 2008;189:72-7.

32. Fortin M, Hudon C, Haggerty J, et al. Prevalence estimates of multimorbidity: a comparative study of two sources. BMC Health Serv Res 2010;10:111. 
33. Taylor AW, Price K, Gill TK, et al. Multimorbidity - not just an older person's issue. Results from an Australian biomedical study. BMC Public Health 2010;10:718.

34. Fezeu L, Minkoulou E, Balkau B, et al. Association between socioeconomic status and adiposity in urban Cameroon. Int J Epidemiol 2006;35:105-11.

35. Mayosi BM, Flisher AJ, Lalloo UG, et al. The burden of non-communicable diseases in South Africa. Lancet 2009;374:934-47.

36. Nojilana B, Bradshaw D, Pillay-van Wyk V, et al. Persistent burden from non-communicable diseases in South Africa needs strong action. S Afr Med J 2016;106:23-4.

37. National Department of Health $(\mathrm{NDoH})$, Statistics South Africa (Stats SA), South African Medical Research Council (SAMRC), and ICF. South Africa Demographic and Health Survey 2016. Pretoria, South Africa, and Rockville, Maryland, USA: NDoH, Stats SA, SAMRC, and ICF, 2019.

38. Egger M, Johnson LF. Estimating trends in life expectancy in HIV-positive individuals. Lancet Glob Health 2015;3:e122-3.

39. Casper C, Crane H, Menon M, et al. HIV/AIDS Comorbidities: Impact on Cancer, Noncommunicable Diseases, and Reproductive Health. In: Holmes KK, Bertozzi S, Bloom BR, et al. editors. Major Infectious Diseases. Washington (DC): The International Bank for Reconstruction and Development/The World Bank, 2017.

40. Alaba O, Chola L. The social determinants of multimorbidity in South Africa. Int J Equity Health 2013;12:63.

41. Barnett K, Mercer SW, Norbury M, et al. Epidemiology of multimorbidity and implications for health care, research, and medical education: a cross-sectional study. Lancet 2012;380:37-43.

42. Steyn K, Damasceno A. Lifestyle and Related Risk Factors for Chronic Diseases. In: Jamison DT, Feachem RG, Makgoba $M W$, et al. editors. Disease and Mortality in Sub-Saharan Africa. Washington (DC): The International Bank for Reconstruction and Development/The World Bank, 2006.

43. Bibbins-Domingo K, Chertow GM, Coxson PG, et al. Projected effect of dietary salt reductions on future cardiovascular disease. N Engl J Med 2010;362:590-9.

44. Imamura F, Micha R, Khatibzadeh S, et al. Dietary quality among men and women in 187 countries in 1990 and 2010: a systematic assessment. Lancet Glob Health 2015;3:e132-42.

45. Maimela E, Alberts M, Modjadji SE, et al. The Prevalence and Determinants of Chronic Non-Communicable Disease Risk Factors amongst Adults in the Dikgale Health Demographic and Surveillance System (HDSS) Site, Limpopo Province of South Africa. PLoS One 2016;11:e0147926.

46. Bhimma R, Naicker E, Gounden V, et al. Prevalence of
Primary Hypertension and Risk Factors in Grade XII Learners in KwaZulu-Natal, South Africa. Int J Hypertens 2018;2018:3848591.

47. Kruger R, Kruger HS, Macintyre UE. The determinants of overweight and obesity among 10- to 15-year-old schoolchildren in the North West Province, South Africa - the THUSA BANA (Transition and Health during Urbanisation of South Africans; BANA, children) study. Public Health Nutr 2006;9:351-8.

48. Lunyera J, Kirenga B, Stanifer JW, et al. Geographic differences in the prevalence of hypertension in Uganda: Results of a national epidemiological study. PLoS One 2018;13:e0201001.

49. WHO. Global status report on non-communicable diseases 2010. Geneva, Switzerland: World Health Organization, 2011.

50. Levitt NS, Steyn K, Dave J, et al. Chronic noncommunicable diseases and HIV-AIDS on a collision course: relevance for health care delivery, particularly in low-resource settings--insights from South Africa. Am J Clin Nutr 2011;94:1690S-1696S.

51. Bawah A, Houle B, Alam N, et al. The Evolving Demographic and Health Transition in Four Low- and Middle-Income Countries: Evidence from Four Sites in the INDEPTH Network of Longitudinal Health and Demographic Surveillance Systems. PLoS One 2016;11:e0157281.

52. Maher D, Smeeth L, Sekajugo J. Health transition in Africa: practical policy proposals for primary care. Bull World Health Organ 2010;88:943-8.

53. Ladusingh L, Mohanty SK, Thangjam M. Triple burden of disease and out of pocket healthcare expenditure of women in India. PLoS One 2018;13:e0196835.

54. Sliwa K, Azibani F, Baard J, et al. Reducing late maternal death due to cardiovascular disease - A pragmatic pilot study. Int J Cardiol 2018;272:70-6.

55. Sliwa K, Libhaber E, Elliott C, et al. Spectrum of cardiac disease in maternity in a low-resource cohort in South Africa. Heart 2014;100:1967-74.

56. Council MR. Burden of Health \& Disease in South Africa: Medical Research Council briefing. 2016. [cited May 2019]. Available online: https://pmg.org.za/committeemeeting/22198/

57. Times F. African cities surge to top of global growth league. 2018. Available online: https://www.ft.com/ content/9d457d54-b272-11e8-8d14-6f049d06439c. Accessed 24 June 2019.

58. Tong S, Ebi K. Preventing and mitigating health risks of climate change. Environ Res 2019;174:9-13.

59. Oni T, McGrath N, BeLue R, et al. Chronic diseases and multi-morbidity--a conceptual modification to the WHO 
ICCC model for countries in health transition. BMC Public Health 2014;14:575.

60. Muth C, van den Akker M, Blom JW, et al. The Ariadne principles: how to handle multimorbidity in primary care consultations. BMC Med 2014;12:223.

61. Battegay E, Cheetham M, Holzer BM, et al. Multimorbidity management and the physician's daily clinical dilemma. Internist (Berl) 2017;58:344-53.

62. Uhlig K, Leff B, Kent D, et al. A framework for crafting clinical practice guidelines that are relevant to the care and management of people with multimorbidity. J Gen Intern Med 2014;29:670-9.

63. Gutermann IK, Niggemeier V, Zimmerli LU, et al. Gastrointestinal bleeding and anticoagulant or antiplatelet drugs: systematic search for clinical practice guidelines. Medicine (Baltimore) 2015;94:e377.

64. Gassmann D, Cheetham M, Siebenhuener K, et al. The multimorbidity interaction severity index (MISI): A proof of concept study. Medicine (Baltimore) 2017;96:e6144.

65. Markun S, Holzer BM, Rodak R, et al. Therapeutic conflicts in emergency department patients with multimorbidity: a cross-sectional study. PLoS One 2014;9:e110309.

66. Sliwa K, Carrington MJ, Becker A, et al. Contribution of the human immunodeficiency virus/acquired immunodeficiency syndrome epidemic to de novo presentations of heart disease in the Heart of Soweto Study cohort. Eur Heart J 2012;33:866-74.

67. Thienemann F, Sliwa K, Rockstroh JK. HIV and the heart: the impact of antiretroviral therapy: a global perspective. Eur Heart J 2013;34:3538-46.

68. WHO. WHO case definitions of HIV for surveillance and revised clinical staging and immunological classification of HIV-related disease in adults and children. Geneva, Switzerland: World Health Organization, 2007.

69. Dave JA, Lambert EV, Badri M, et al. Effect of nonnucleoside reverse transcriptase inhibitor-based antiretroviral therapy on dysglycemia and insulin sensitivity in South African HIV-infected patients. J Acquir Immune Defic Syndr 2011;57:284-9.

70. Dillon DG, Gurdasani D, Riha J, et al. Association of HIV and ART with cardiometabolic traits in sub-Saharan Africa: a systematic review and meta-analysis. Int J Epidemiol 2013;42:1754-71.

71. Kovari H, Calmy A, Doco-Lecompte T, et al. Antiretroviral Drugs Associated with Subclinical Coronary Artery Disease in the Swiss HIV Cohort Study. Clin Infect Dis 2020;70:884-9.

72. Guthrie B, Payne K, Alderson P, et al. Adapting clinical guidelines to take account of multimorbidity. BMJ 2012;345:e6341.
73. Marengoni A, Rizzuto D, Wang HX, et al. Patterns of chronic multimorbidity in the elderly population. J Am Geriatr Soc 2009;57:225-30.

74. Aidoo M, Terlouw DJ, Kolczak MS, et al. Protective effects of the sickle cell gene against malaria morbidity and mortality. Lancet 2002;359:1311-2.

75. Makani J, Komba AN, Cox SE, et al. Malaria in patients with sickle cell anemia: burden, risk factors, and outcome at the outpatient clinic and during hospitalization. Blood 2010;115:215-20.

76. Clumeck N, Pozniak A, Raffi F, et al. European AIDS Clinical Society (EACS) guidelines for the clinical management and treatment of HIV-infected adults. HIV Med 2008;9:65-71.

77. Census 2011: Profile of older persons in South Africa, Report 03-01-60 2011. Available online: http:// www.statssa.gov.za/publications/Report-03-01-60/ Report-03-01-602011.pdf

78. Kowal P, Kahn K, Ng N, et al. Ageing and adult health status in eight lower-income countries: the INDEPTH WHO-SAGE collaboration. Glob Health Action 2010. doi: 10.3402/gha.v3i0.5302.

79. WHO. Declaration of Alma-Ata. Geneva, Switzerland: World Health Organization, 1978.

80. WHO. The aids response and primary health care: linkages and opportunities. Geneva, Switzerland: World Health Organization, 2018.

81. General Assembly. Political Declaration on HIV and AIDS: On the Fast Track to Accelerating the Fight against HIV and to Ending the AIDS Epidemic by 2030. United Nations, 2016.

82. Uyei J, Coetzee D, Macinko J, et al. Measuring the degree of integrated tuberculosis and HIV service delivery in Cape Town, South Africa. Health Policy Plan 2014;29:42-55.

83. Scott VE, Sanders D. Evaluation of how integrated HIV and TB programs are implemented in South Africa and the implications for rural-urban equity. Rural Remote Health 2013;13:2165.

84. Dudley L, Garner P. Strategies for integrating primary health services in low- and middle-income countries at the point of delivery. Cochrane Database Syst Rev 2011;(7):CD003318.

Cite this article as: Thienemann F, Ntusi NAB, Battegay E, Mueller BU, Cheetham M. Multimorbidity and cardiovascular disease: a perspective on low- and middle-income countries. Cardiovasc Diagn Ther 2020;10(2):376-385. doi: 10.21037/ cdt.2019.09.09 